\title{
An anterior neurovascular interval approach to coronal shear fractures of the distal humerus: a prospective clinical study with short- to mid-term follow-up
}

\author{
(D) Xiao-Hua Yang ${ }^{1}$ \\ (iDChen Wei \\ (i) Guo-Ping Li ${ }^{1}$ \\ (iD) Jian-ji Wang ${ }^{1}$ \\ id Hai-Tao Zhao' \\ (iD Li-Tao Shi ${ }^{1}$ \\ (D) Xiang-Yu Cao' \\ (D) Ying-Ze Zhang ${ }^{2}$
}

1. The Second Department of Orthopaedics, The Affiliated Hospital of Chengde Medical College, Chengde 067000, China 2. Emergency Center of Trauma, The Third Hospital of Hebei Medical University, Shijiazhuang 050051, China

http://dx.doi.org/10.1590/1806-9282.65.3.355

\section{SUMMARY}

OBJECT: To explore the treatment effect of the anterior medial neurovascular interval approach to coronal shear fractures of the distal humerus.

METHODS: This prospective study included two female patients who were 30-64 years old, with a mean age of 47 years. Fractures were caused by falling from a bicycle. The time between the injury and operation was 1-2 days, with a mean time interval of 1.5 days. Two patients with coronal shear fracture of the distal humerus were treated with open reduction and internal fixation using anterior neurovascular interval approach.

RESULTS: There were no intraoperative and postoperative neurological and vascular complications or infections, and the fracture was united. At 12 months after the surgery, the patient returned to work without pain, and with a normal range of motion for elbow and forearm rotation. The X-rays revealed excellent fracture union, no signs of heterotopic ossification, and no traumatic arthritis. According to Mayo's evaluation standards for elbow function, a score of 100 is excellent.

CONCLUSIONS: The application of the anterior neurovascular interval approach of the elbow in the treatment of shear fracture of the articular surface of the distal humerus, particularly the trochlea of the humerus, can reduce the stripping of the soft tissue.

KEYWORDS: anatomy, anterior approach, elbow joint, neurovascular interval, coronal, shear, fracture, distal, humerus, reduction, and internal fixation.

\section{INTRODUCTION}

Coronal shear fractures of the distal humerus are rare and complex and have become a challenge for orthopedists $^{1-3}$. Insufficient soft tissue attachments at the fracture site often contribute to displacement ${ }^{2}$, which determines the need for surgery. Determining a good surgical approach is crucial to ensure the success of the surgery and reduce complications such as joint stiffness, joint pain, osteoarthritis, heterotopic ossification, instability of the elbow and limited elbow function activity. Medial and lateral approach- 
es require excessive soft tissue dissection, making exposure and fixation more difficult; while the posterior approach is often combined with olecranon osteotomy. Thus, these three approaches have limitations ${ }^{4,5}$. The application of the anterior approach has also been reported ${ }^{6}$ to have an advantage of performing fewer dissections, which is more applicable for capitellum fractures.

According to anatomical findings of the anterior neurovascular interval of the elbow, we applied a different anterior approach to treat shear fractures of the distal humeral articular surface, especially fractures at the trochlear region. This approach has various advantages, including a simple anatomical layer, it is easy to master, the tissues are moderately dissected during surgery, fewer side injuries, easy to expose, provides a clear operative field, reduces direct visualization and strong operability. These are reported as follows.

\section{MATERIALS AND METHODS}

\section{General Information}

This prospective study included two females aged between 30-64 years, with a mean age of 47 years. Their fractures were caused by a bicycle fall. The time between the injury and the operation was 1-2 days, with a mean interval of 1.5 days. Both patients with coronal shear fracture of the distal humerus were treated with open reduction and internal fixation by the anterior neurovascular interval approach. Reduction and fixation of the coronoid fracture were performed through the same approach on one patient with an ulna coronoid process fracture, while in another patient with a fracture of the lateral epicondyle of the humerus the fixation of the fracture was performed through another incision. Plaster splints were used for fixation in both patients, and function exercises were performed after the removal of the external fixation at 2-3 weeks postoperative.

Typical case: A 64-year-old female fell off the bicycle and got injured when her right hand and forearm hit the ground. Her right elbow was swollen and painful with limited mobility. She presented to the Emergency Department of our hospital 30 minutes after the injury. Upon examination, the right elbow was swollen with local ecchymosis and tenderness, as well as an elbow flexion of $30^{\circ}$. Elbow flexion/extension and forearm rotation were limited. No signs of neurovascular injury were detected, radial artery pulse was good, and the right wrist and fingers moved easily. After checking the vital signs of the patient admitted to the hospital, X-ray, CT scan, and three-dimensional imaging examinations revealed a coronal shear fracture of the distal humerus, which was comminuted and affected the lateral epicondyle of the humerus; the fracture surface was sagittal. Various routine examinations were performed before surgery for perioperative preparation.

The patient received an open reduction and internal fixation (ORIF) 48 hours after the injury. The patient was placed in supine position, and the operative elbow was extended on a see-through operating table, without a tourniquet. Based on the following surgical technique, the fracture of the distal humeral articular surface was exposed for anatomical reduction of fractures. At the trochlear region of the articular surface, three 2.0-mm bioabsorbable screws (provided by Inion, Finland) were fixed from front to back, perpendicular to the fracture surface. The lateral epicondyle connected to the capitellum was a whole bone. Another 2-cm small incision was made on the lateral side, and two 1.2-mm Kirschner wires were used for fracture fixation vertical to the fracture surface of the epicondyle. Due to the anatomical reduction of the fracture and reliable fixation, no elbow instability was detected after the surgery. Indomethacin was administered at the early stage after the injury to prevent heterotopic ossification. A functional plaster slab was provided for immobilization after surgery, as well as routine anti-inflammatory and anti-swelling treatment.

\section{Surgical techniques}

Under brachial plexus block anesthesia, the patient was placed in the supine position; and the operative elbow was extended on the operating table. A "S" type incision started $2 \mathrm{~cm}$ proximal to the elbow flexion crease, curved cross the elbow crease, and extended distally along the radial border of the forearm at approximately $2 \mathrm{~cm}$ distal to the flexion crease. During the skin incision, the main superficial veins were identified and protected to ensure non-ligation and ready extraction. Careful blunt subcutaneous dissection was performed to expose the medial antebrachial cutaneous nerve, which should be protected and retracted medially. The deep fascia, biceps, and bicipital aponeurosis were unroofed, as well as the distal brachioradialis and pronator teres. The trans- 
verse split of the bicipital aponeurosis provided excellent exposure of the proximal brachial artery and vein, as well as the median nerve. The latter extended distally from the space between the humeral head of the pronator teres muscle and ulnar head. The brachioradialis and pronator teres muscle were separated for distal exposure. The clearance between the brachial artery and median nerve allowed insertion due to a loose structure and absence of neurovascular branches. The brachial artery, biceps tendon, and brachioradialis were retracted laterally, while the median nerve and pronator teres were retracted medially, providing the best exposure of the brachial muscle. The longitudinal muscle split and retraction accomplished good visualization of the anterior capsule and displaced fragment of the coronal fracture of the distal humerus. The anatomical reduction of the fracture was performed under direct visualization, followed by front-to-back fixation with headless compression screws or absorbable screws (Figure 1).

\section{Postoperative management and follow-up}

The suture was removed two weeks after surgery, followed by the removal of the plaster slab two weeks later. Functional exercises were initiated with a small ROM, combining active and passive activities. After removing the Kirschner wires four weeks later, ROM was gradually increased, and regular functional training was appointed. ROM was increased moderately every 3-5 days. After eight weeks, both elbow flexion/ extension and forearm pronation/supination were restored to normal, followed by fracture healing three months after the surgery. The patient was followed-up regularly at 1, 3, 6 and 12 months (Figure 2).

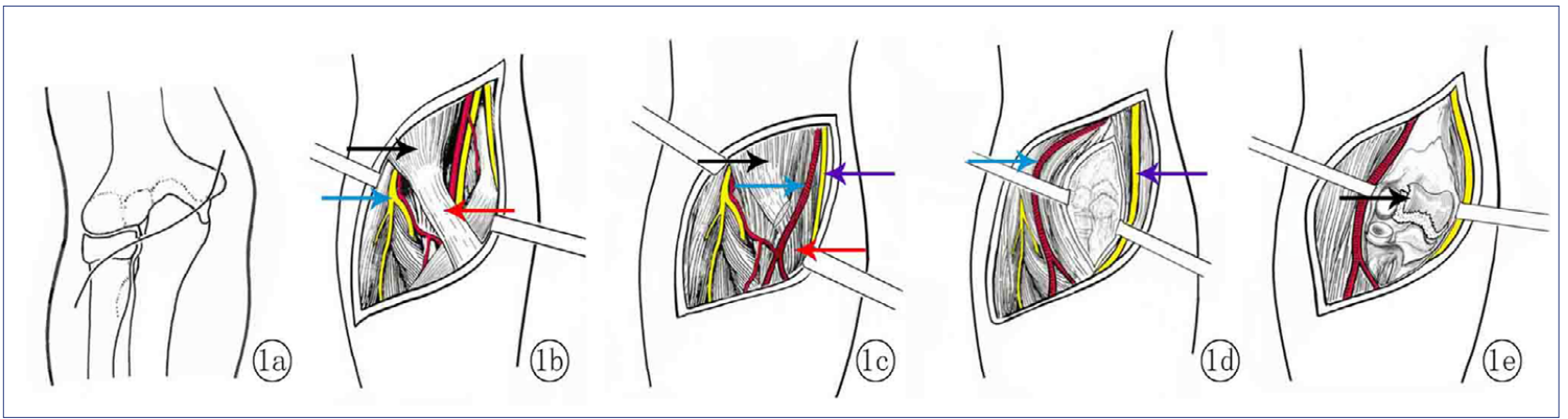

FIGURE 1. Illustration of the anterior neurovascular interval approach of the elbow. a. "S" shaped incision in the front of elbow joint; b. Exposure of biceps (black arrow) and bicipital aponeurosis (red arrow), lateral cutaneous nerve of the forearm (blue arrow) after subcutaneous dissection; c. Horizontal incision of bicipital aponeurosis, showing biceps (black arrow), part of pronator teres (red arrow), brachial artery (blue arrow), and median nerve (purple arrow); d. Entering through the neurovascular interval, biceps and brachial artery (blue arrow) to the lateral side, and pronator teres, median nerve (purple arrow) to the medial side, exposure and longitudinally splitting of brachial muscle and distraction; e. Exposure of trochlea fracture fragment (black arrow)
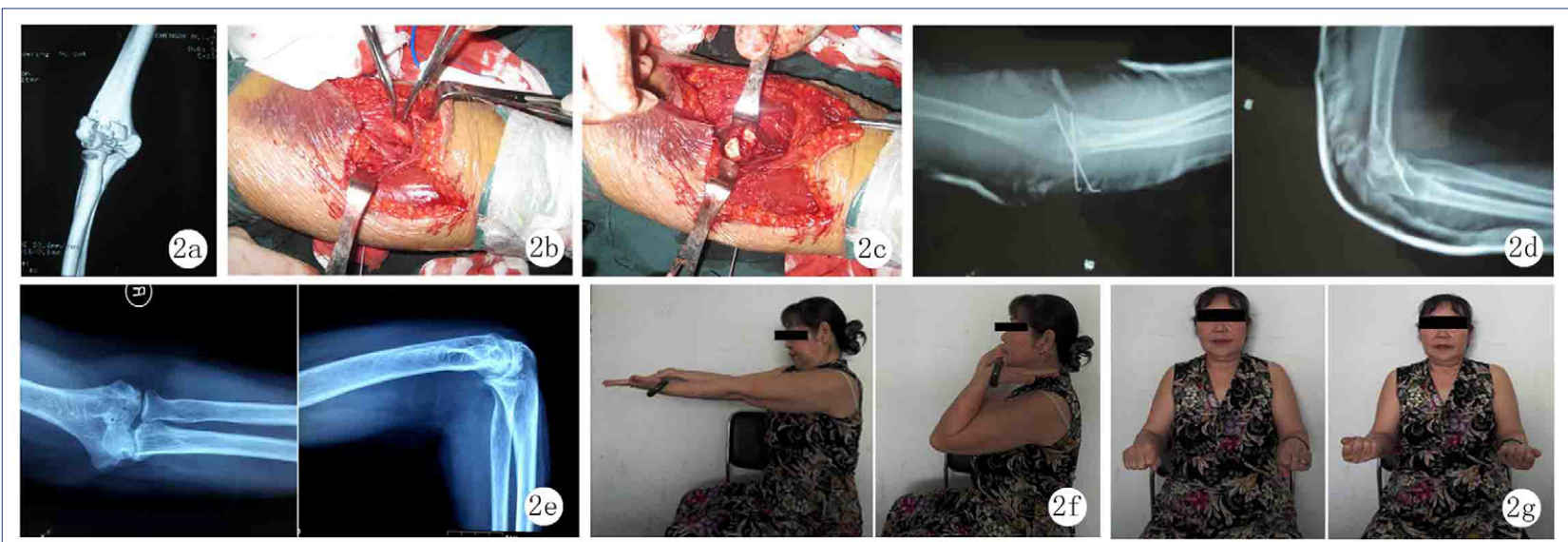

FIGURE 2. A 64-year-old female patient with coronal shear fractures of the right distal humerus a. Preoperative three-dimensional CT image; b. Exposure of brachial artery and median nerve in operation; c. Exposure of trochlea fracture fragment in operation; d. Anteroposterior and lateral X-rays 2 days after the operation; e. Anteroposterior and lateral X-rays 1 year after the operation; f. Function of the flexion and extension of the elbow 1 year after the operation; g. Function of the pronation and supination of the arm 1year after the operation 


\section{RESULTS}

The patient revealed no intraoperative and postoperative neurovascular complications, and no deep infection, with a Class-A healing rate. Elbow function was restored to normal during the 12-month follow-up. Furthermore, the patient was able to resume her job and reported no complications such as pain, heterotopic ossification, traumatic arthritis, and poor joint mobility. The arc of the elbow flexion and extension was $135^{\circ}$, and the forearm pronation/ supination was $155^{\circ}$. Based on the evaluation criteria of elbow performance by Mayo, the result was categorized as excellent.

\section{DISCUSSION}

Shear fractures of the distal humeral articular surface are a relatively rare intra-articular fracture that often leads to displacement. Conservative treatment provides poor outcomes and often contributes to complications such as chronic pain, instability, and mechanical symptoms of joints ${ }^{1-3}$. Its principles of treatment include the anatomical reduction of the fracture, restoration of the smooth articular surface, strong and reliable internal fixation, and early functional exercises, thereby reducing the non-osteoporosis complications of the elbow including arthritis, pain, joint stiffness and joint instability ${ }^{2}$. Basically, all patients require surgery, including ORIF. Arthroscopic-assisted surgery has also been reported. In terms of severely comminuted fractures that could not be fixed, total elbow replacement surgery is viable ${ }^{7}$. ORIF surgery can produce superior therapeutic effects in most patients with coronal shear fracture of the distal humerus. This effect derives from the anatomic reduction of fractures and stable fixation, as well as early and active function exercises on this basis'.Coronal shear fractures of the distal humerus represent significant articular injuries and are usually more complex than those suggested by radiographic imaging. The fracture pattern and extent of articular involvement dictate the method of surgical exposure and the internal fixation technique used for treatment ${ }^{8}$.The complexity of elbow injuries and pathology requires a surgeon to be comfortable with a range of approaches to the elbow joint. In trauma, the selection of the most helpful approach is determined by a combination of experience and familiarity with the anatomy interpreted to the fracture pattern. This enables the optimal exposure of relevant parts of the elbow joint ${ }^{9}$. Good surgical approaches are necessary for a successful operation. Multiple surgical approaches have been described for coronoid repair $^{10}$. There are several treatment options similar to those that concern shear fracture of the distal humeral articular surface, which include the extensile lateral approach, the posterior approach with olecranon osteotomy, and the anterolateral approach. The extensile lateral approach has the disadvantages of excessive soft tissue dissection around the joint and great damage ${ }^{11}$. Furthermore, we believe that this approach is preferable for humeral head fractures. However, it is difficult to expose the ulnar side of the distal humerus. The posterior approach is often combined with olecranon osteotomy, therefore bringing about the extension of the fracture, the risk of nonunion olecranon, and complications caused by the internal fixator ${ }^{12}$. Therefore, we also assume that this approach is applicable to free-bone fractures of the anterior elbow joint. Furthermore, it has also been reported in the literature that for the anterolateral approach, an incision is made at the space between the lateral biceps tendon and brachioradialis, where the radial nerve passes and the nerve branches are given off. This would easily damage these branches. The function of nerve branches is difficult to restore after injury. In addition, the biceps tendon ends at the radial tuberosity. Hence, it is more difficult to expose the ulnar side of the distal humerus by medial retraction. Therefore, this approach is also more applicable for radial fractures of the distal humerus, such as fractures of the humeral head. Some scholars have applied two surgical approaches, called the combination of the lateral and anterior approaches, which can reduce soft tissue dissection. The anterior approach is similar to the approach for the fixation of ulna coronoid fractures. However, through this approach, the incision is made at the space between the biceps nerve and vascular bundles ${ }^{13}$. The ideal surgical approach for elbow fracture should be the one that requires as little surgical dissection as possible, does not affect the visualization of the fracture, and has minimal risk of heterotopic ossification and elbow stiffness ${ }^{14}$. In this study, despite the similar skin incision induced through the anterior approach and other anterior approaches that have been reported, the specific tissue space selected in this approach is different from other anterior approaches. As for the superficial layer of the deep fascia, other reports ${ }^{15,16}$ revealed that the brachial artery and the median 
nerve were retracted to one side; while in our study, we made an incision space between the brachial artery and median nerve. The separation was available due to the loose and wide space. The brachial artery, biceps tendon, and brachioradialis were retracted laterally, while the median nerve and pronator teres were retracted medially, providing the best exposure of the brachial muscle. The longitudinal muscle split and retraction accomplished a good visualization of the anterior capsule and anterior humeral fracture. Through the anatomical study of cadavers, we found that the brachial artery and vein were accompanied by the median nerve for a long distance, and there were no branches traveled across them. Furthermore, the brachial artery had no medial branches but lateral ones, which nourished muscles such as the brachioradialis and supinator muscle. In contrast, the median nerve has no lateral branches except for medial ones, which control the pronation teres, flexor carpi radialis, and musculus flexor digitorum sublimis. The gap between these two was very loose to be separated and retracted easily. However, anatomical studies also have variations. Based on local anatomical characteristics, we propose that an incision is made at the space between the brachial artery and median nerve. Due to elbow flexion/extension functions, nerves, and blood vessels, this site has great ROM for retraction to both sides, causing no neurovascular complications. This approach avoids medial retraction of the neurovascular bundle, therefore preventing the branches of the brachial artery from being cut off. Some scholars ${ }^{17}$ have questioned the reports provided by Han $\mathrm{SH}$ et al. Some arterial branches constitute a "vascular tree"; therefore, the distance of the brachial artery retracted medially was constricted. What is the best option to manage arterial branches? An incision made at the space between the brachial artery and the median nerve was the optimal approach. This reduced injury to vascu- lar branches and intraoperative bleeding, and saved operation time. Additionally, lateral retraction to expose the blood vessels and nerves would damage the medial branches of the median nerve, resulting in neurological symptoms, which have been reported by some scholars ${ }^{18}$. There are several ways to fix coronal shear fractures of the distal humerus, and the most commonly used ones include headless compression screws. Absorbable screws were applied to the patient reported in our study. We presume that both can be used for articular fractures producing good therapeutic effects. The biomechanical experiments conducted by Elkowitz et al. ${ }^{19}$ revealed that front-to-back fixation with headless compression screws was superior to back-to-front fixation with cancellous bone screws. Front-to-back vertical fixation is the most stable one in coronal shear fractures, and this approach is convenient for the front-to-back placement of the fixator, especially for intra-articular fractures, free-anterior fracture blocks, and fractures with coronal planes. Moreover, with this approach, less soft tissue dissection contributes to anatomical reduction and stable fixation, reducing complications such as arthritis, nonunion, pain, stiffness, and heterotopic ossification. The limitation of this study is its small sample size. Therefore, studies with large sample sizes are needed to accumulate experience.

\section{CONCLUSIONS}

The anterior neurovascular interval approach of the elbow can be used for the treatment of shear fractures of the distal humeral articular surface, especially the trochlea. This approach reduces the dissection of soft tissue, ensures the most significant exposure, reduces fracture and fixation under direct visualization, and reduces complications. It can be applied either alone or in combination with other surgical approaches, producing optimal therapeutic effects.

\section{RESUMO}

OBJETIVO: Explorar o efeito do tratamento com uma abordagem anterior do intervalo neurovascular médio para fraturas de cisalhamento coronal da porção distal do úmero.

METODOlogiA: Este estudo prospectivo incluiu duas pacientes do sexo feminino de 30-64 anos de idade, com idade média de 47 anos. As fraturas foram causadas por quedas de bicicleta. O tempo entre a lesão e a operação foi de 1-2 dias, com um intervalo de tempo médio de 1,5 dias. Duas pacientes com cisalhamento coronal da porção distal do úmero foram tratadas com redução aberta e fixação interna utilizando a abordagem anterior do intervalo neurovascular.

RESULTADOS: Não houve complicações neurológicas e vasculares intra e pós-operatórias, nem complicações ou infecções, e a fratura foi unida. Após 12 meses da cirurgia, as pacientes retornaram ao trabalho sem dor e com uma amplitude normal de movimento de rotação do antebraço e cotovelo. Os raios-X revelaram excelente união das fraturas, sem sinais de ossificação heterotópica e sem artrite traumática. De acordo com as diretrizes da clínica Mayo para avaliação da função do cotovelo, uma pontuação de 100 é considerada excelente. 
CONCLUSÃO: A aplicação da abordagem anterior do intervalo neurovascular do cotovelo no tratamento de uma fratura de cisalhamento da superfície articular da porção distal do úmero, especificamente da tróclea do úmero, pode reduzir o desgaste do tecido mole.

PALAVRAS-CHAVE: Anatomia; abordagem anterior; articulação do cotovelo; intervalo neurovascular; processo coronóide da ulna; redução; fixação interna.

\section{REFERENCES}

1. Nauth $A$, McKee MD, Ristevski B, Hall J, Schemitsch EH. Distal humeral fractures in adults. J Bone Joint Surg Am 2011; 93: 686-700.

2. Lee JJ, Lawton JN. Coronal shear fractures of the distal humerus. J Hand Surg Am 2012; 37: 2412-2417.

3. Ruchelsman DE, Tejwani NC, Kwon YW, Egol KA. Coronal plane partial articular fractures of the distal humerus: current concepts in management. Am Acad Orthop Surg 2008; 16: 716-728.

4. Watts AC, Morris A, Robinson CM. Fractures of the distal humeral articular surface. J Bone Joint Surg Br 2007; 89: 510-515.

5. Guitton TG, Doornberg JN, Raaymakers EL, Ring D, Kloen P. Fractures of the capitellum and trochlea. J Bone Joint Surg Am 2009; 91: 390-397.

6. Ruchelsman DE, Tejwani NC, Kwon YW, Egol KA. Open reduction and internal fixation of capitellar fractures with headless screws. Surgical technique. J Bone Joint Surg Am 2009; 91 Suppl 2 Pt 1: 38-49.

7. Kuriyama K, Kawanishi Y, Yamamoto K. Arthroscopic-assisted reduction and percutaneous fixation for coronal shear fractures of the distal humerus: report of two cases. J Hand Surg Am 2010; 35: 1506-1509.

8. Shahram S Y, Nathan L B, Miguel A C, Lee M R. Management of distal humeral coronal shear fractures. World J Clin Cases 2015; 3: 405-417.

9. Chris Peach, David Stanley. Surgical approaches to the elbow. Orthopaedics and Trauma 2012; 26: 297-302.

10. Shukla DR, Koehler SM, Guerra SM, Hausman MR. A novel approach for coronoid fractures. Tech Hand Surg 2014; 18: 189-193.
11. Bilsel K, Atalar AC, Erdil M, Elmadag M Sen C, Demirhan M Coronal plane fractures of the distal humerus involving the capitellum and trochlea treated with open reduction internal fixation. Arch Orthop Trauma Surg 2013; 133: 797-804.

12. Dubberley |H, Faber K|, Macdermid IC, Patterson SD, King Gl.Outcome after open reduction and internal fixation of capitellar and trochlear fractures. J Bone Joint Surg Am 2006; 88: 46-54.

13. Reichel LM, Milam GS, Reitman CA. Anterior approach for operative fixation of coronoid fractures in complex elbow instability. Tech Hand Up Extrem Surg 2012; 16: 98-104.

14. Ring D, Jupiter JB. Surgical Exposure of Coronoid Fractures. Techn Shoulder Elbow Surg 2002; 3: 48-56.

15. O'Driscoll SW, Jupiter JB, Cohen MS, Ring D, McKee MD. Difficult elbow fractures: pearls and pitfalls. Instr Course Lect 2003; 52: 113-134.

16. Han SH, Yoon HK, Rhee SY, Lee JK. Anterior approach for fixation of isolated type III coronoid process fracture. Eur | Orthop Surg Traumatol 2013; 23: 395-405.

17. Zhu XZ, Wang $X, M a Z H$. Comment on the anterior approach for coronoid process fracture. Eur J Orthop Surg Traumatol 2014; 24: 123-124.

18. Zuo YM ,Wang ZHQ, Wang YG, Zhao GZ, Ma SL. Treatment of ulna coronoid fractures. Chin J Orthop 2006; 26: 366-370.

19. Elkowitz SJ, Polatsch DB, Egol KA, Kummer FJ, Koval KJ. Capitellum fractures: a biomechanical evaluation of three fixation methods. J Orthop Trauma 2002; 16: 503-506. 